\title{
Partial uncinatectomy combined with anterior cervical discectomy and fusion for the treatment of one-level cervical radiculopathy: analysis of clinical efficacy and sagittal alignment
}

Haimiti Abudouaini ${ }^{1}$, Tingkui Wu ${ }^{1}$, Hao Liu ${ }^{1 *}$, Beiyu Wang ${ }^{1}$, Hua Chen ${ }^{1}$, Chengyi Huang ${ }^{1}$, Ying Hong ${ }^{2}$ and Yang Meng ${ }^{1}$

\begin{abstract}
Background: Biomechanical studies have demonstrated that uncovertebral joint contributes to segment mobility and stability to a certain extent. Simultaneously, osteophytes arising from the uncinate process are a common cause of cervical spondylotic radiculopathy (CSR). For such patients, partial uncinatectomy (UT) may be required. However, the clinical efficacy and sagittal alignment of partial UT during anterior cervical discectomy and fusion (ACDF) have not been fully elucidated.

Methods: A total of 87 patients who had undergone single level ACDF using a zero-profile device from July 2014 to December 2018 were included. Based on whether the foraminal part of the uncovertebral joint was resected or preserved, the patients were divided into the ACDF with UT group $(n=37)$ and the ACDF without UT group $(n=$ 50). Perioperative data, radiographic parameters, clinical outcomes, and complications were compared between the two groups.

Results: The mean follow-up was $16.86 \pm 5.63$ and $18.36 \pm 7.51$ months in the ACDF with UT group and ACDF without UT group, respectively $(p>0.05)$. The average preoperative VAS arm score was $5.89 \pm 1.00$ in the ACDF with UT group and $5.18 \pm 1.21$ in the ACDF without UT group ( $p=0.038)$. However, the average VAS arm score was $4.22 \pm 0.64,4.06 \pm 1.13$ and $1.68 \pm 0.71,1.60 \pm 0.70$ at 1 week post operation and at final follow up, respectively, $(p>$ 0.05). We also found that the C2-7 SVA and St-SVA at the last follow-up and their change (last follow-up value preoperative value) in the ACDF with UT group were significantly higher than ACDF without UT group $(p<0.05)$. No marked differences in the other cervical sagittal parameters, fusion rate or complications, including dysphagia, ASD, and subsidence, were observed.
\end{abstract}

\footnotetext{
*Correspondence: liuhaospine@163.com

'Department of Orthopedic Surgery, West China Hospital, Sichuan University, No. 37 Guo Xue Xiang Rd, Chengdu, China

Full list of author information is available at the end of the article
}

(C) The Author(s). 2021 Open Access This article is licensed under a Creative Commons Attribution 4.0 International License, which permits use, sharing, adaptation, distribution and reproduction in any medium or format, as long as you give appropriate credit to the original author(s) and the source, provide a link to the Creative Commons licence, and indicate if changes were made. The images or other third party material in this article are included in the article's Creative Commons licence, unless indicated otherwise in a credit line to the material. If material is not included in the article's Creative Commons licence and your intended use is not permitted by statutory regulation or exceeds the permitted use, you will need to obtain permission directly from the copyright holder. To view a copy of this licence, visit http://creativecommons.org/licenses/by/4.0/. The Creative Commons Public Domain Dedication waiver (http://creativecommons.org/publicdomain/zero/1.0/) applies to the data made available in this article, unless otherwise stated in a credit line to the data. 
Conclusions: Our result indicates that ACDF using a zero-p implant with or without partial UT both provide satisfactory clinical efficacy and acceptable safety. However, additional partial UT may has a negative effect on cervical sagittal alignment.

Keywords: Anterior cervical discectomy and fusion, Incinatectomy, Uncovertebral joint, Sagittal alignment, Cervical spondylotic radiculopathy

\section{Introduction}

Cervical spondylotic radiculopathy (CSR) is one of the most common spinal diseases seen in clinical practice. There is an annual incidence of 107.3 per 100,000 for men and 63.5 per 100,000 for women, with a peak incidence in the fourth and fifth decades of life $[1,2]$. CSR is defined as neck pain in a radicular pattern in one or both upper extremities related to compression and/or irritation of one or more cervical nerve roots. Anterior cervical discectomy and fusion (ACDF) has become a widely accepted and time-tested surgical intervention for the treatment of CSR patients who are nonresponsive to conservative treatment [3]. Clinical and radiologic results after ACDF appear to be good [4-6]. However, for CSR patients with foraminal stenosis, it is difficult to achieve complete nerve root decompression only by simple discectomy, and such patients often do not have obvious root symptom relief after surgery or have a recurrence after temporary relief [7-9]. Although uncovertebral osteophytes are reported to be the most common cause of nerve root compression in cervical spondylosis [10, 11], the necessity and optimal surgical method of UT in ACDF surgery have been still controversial.

Due to the absence of anterior plates, it is theoretically possible that zero-profile implants worsen the maintenance of cervical sagittal balance compared to traditional cervical plates and cage implants. Moreover, since it was reported that uncovertebral join contributes to spinal motion segment mobility and stability [12, 13], we hypothesized that resecting the uncinate processes during $\mathrm{ACDF}$ using a zero-profile implant may cause postoperative sagittal imbalance. However, previous studies related to uncinatectomy during ACDF mainly focus on efficacy, surgical techniques and complications $[2,7,9,14-18]$ and its effect on the cervical sagittal balance was not fully explored.

Thus, considering the paucity of clinical data in this field, a retrospective analysis was performed to investigate the effect of uncinectomy on sagittal parameters by comparing the clinical and radiologic outcomes after ACDF with partial uncinatectomy (UT) versus ACDF without UT.

\section{Materials and methods}

\section{Patient recruitment and inclusion criteria}

We retrospectively reviewed all one-level ACDF cases with a zero-profile device (Zero-P, Synthes GmbH,
Switzerland) for spondylotic radiculopathy from July 2014 to December 2018 performed by the same senior spine surgeon in our department with a minimum of 1year clinical follow-up. Indications for surgery included patients with radiculopathy secondary to herniated disc, spondylosis, or a combination of both that was refractory to conservative treatment.

The inclusion criteria included the following: (1) patients with symptoms of degenerative cervical disease; (2) patients who received only single level ACDF; and (3) a follow-up period greater than 12 months. The exclusion criteria were as follows: (1) patients who had a history of previous cervical spine surgery, fractures, tumours, etc.; (2) patients who underwent multilevel ACDF; (3) patients with myelopathy, congenital cervical malformation, ankylosing spondylitis, severe osteoporosis (T-score $\leq-2.5)$, rheumatoid arthritis, cervical infection, pregnancy, metal allergy, or a neuromuscular disease; and (4) Patients with bilateral uncinatectomy; (5) a follow-up period of less than 12 months.

Partial uncinatectomy was defined as using a highspeed matchstick burr to remove the foraminal part of the uncovertebral joint [19], while no uncinatectomy was defined as preserve the uncinate process intact (Fig. 1). This was confirmed with postoperative computed tomography scans and medical records.

\section{Surgical technique}

A standard Smith-Robinson anteromedial left-sided cervical approach was used in all cases. After sufficient exposure, complete discectomy was performed at the index levels by removing the disc tissue, posterior longitudinal ligament and osteophytes to achieve thorough decompression. Evidence of foraminal stenosis due to uncovertebral joint hypertrophy was confirmed by preoperative imaging and intraoperative exploration. For these patients, a high-speed matchstick burr was used to remove the hyperplastic osteophytes and foraminal part of the uncovertebral joint [19]. If the patient had unilateral symptoms and if the radiologic results were consistent, we unilaterally removed the hyperplastic osteophytes and foraminal part of the uncovertebral joint. We used a zero-p implant (Zero-P, Synthes $\mathrm{GmbH}$, Switzerland) filled with a composite synthetic bone graft ( Paoli, CA, USA) implanted into the index levels. The final imaging of the device was performed 


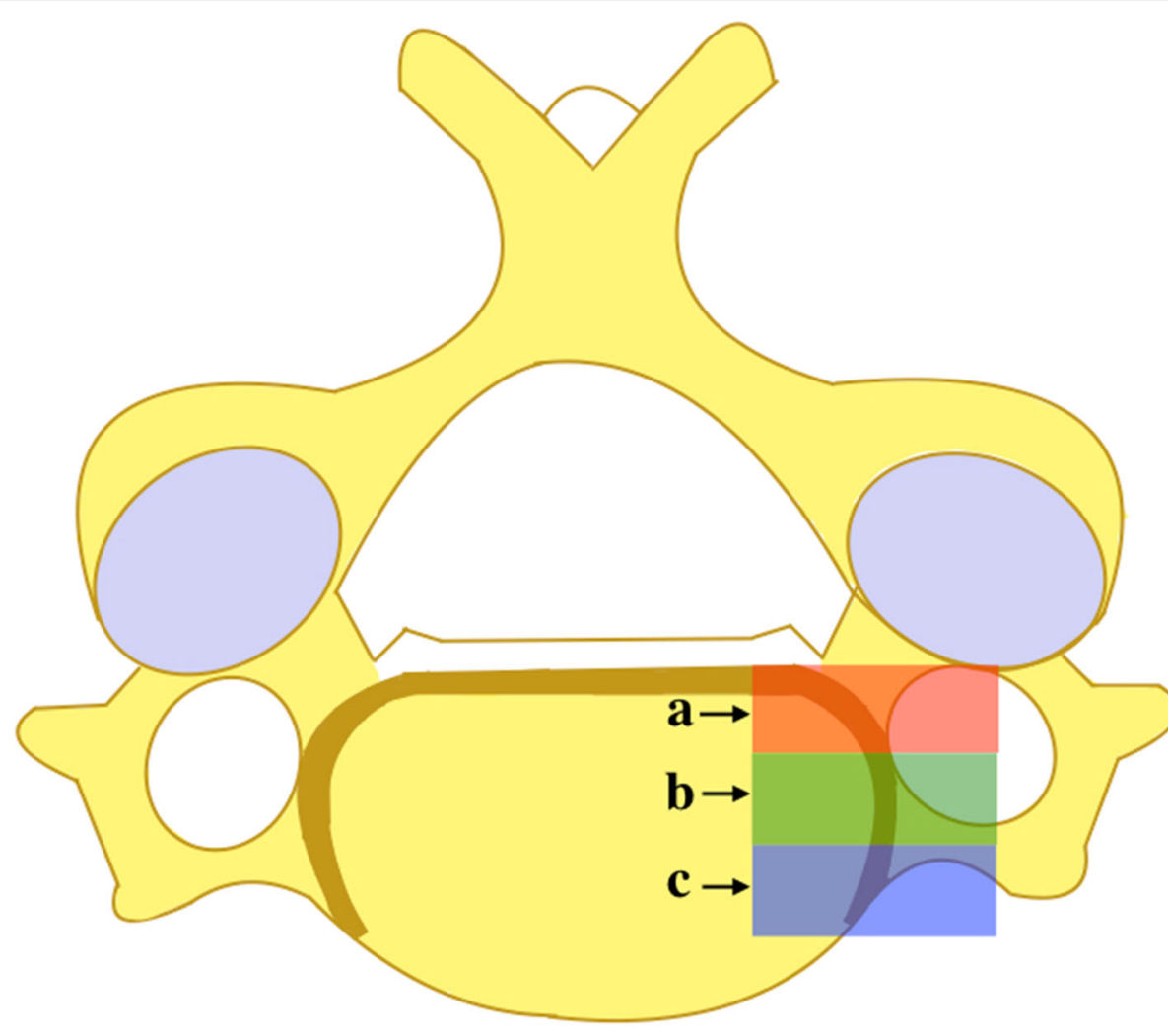

uncovertebral joint

a: foraminal part, b: posterior part, c: anterior part

Fig. 1 Anatomic schematic drawing of the uncovertebral joint

before the locking head screws were screwed. After the surgery, the incision was sutured layer by layer.

\section{Clinical outcome assessment}

Demographic data, including age, sex, body mass index (BMI), intraoperative blood loss and hospital stay days, were obtained from the patient medical records. Clinical outcomes were assessed by the visual analogue scale (VAS), Neck Disability Index (NDI), and Japanese Orthopaedic Association (JOA) score. All clinical evaluations were collected preoperatively, immediately after surgery, and at the last follow-up.

\section{Radiological evaluation}

Radiological analysis was conducted via lateral radiographs for flexion, extension, and neutral positions. All radiographic measurements were performed by two spine surgeons who did not participate in these surgeries. Cervical lordosis (CL), functional spinal unit angle (FSUA), sagittal vertical axis (C2-7 SVA), centre of the sella turcica-C7 sagittal vertical axis (St-SVA), and $\mathrm{T} 1$ slope were recorded according to methods described in previous studies [20, 21] (Fig. 2). CL was measured between the inferior margin of the $\mathrm{C} 2$ vertebrae, and the inferior margin of the $\mathrm{C} 7$ vertebrae was measured as the C2-7 angle. The FSUA was calculated using the Cobb angle of the adjacent vertebrae to the involved intervertebral disc. The $\mathrm{C} 2-\mathrm{C} 7$ SVA was decided as the length from the posterosuperior corner of $\mathrm{C} 7$ and the vertical line from the centre of the $\mathrm{C} 2$ body. The centre of the St-SVA was defined as the distance between a plumb line from the centre of the sellar turcica and the centre of the C7 body. The T1 slope was defined as the angle between the T1 superior endplate and a horizontal line.

\section{Statistical analysis}

All statistical analyses were performed using SPSS 25.0 software (SPSS Inc., Chicago, IL, USA). Continuous data are presented as the means \pm standard deviation, and the 


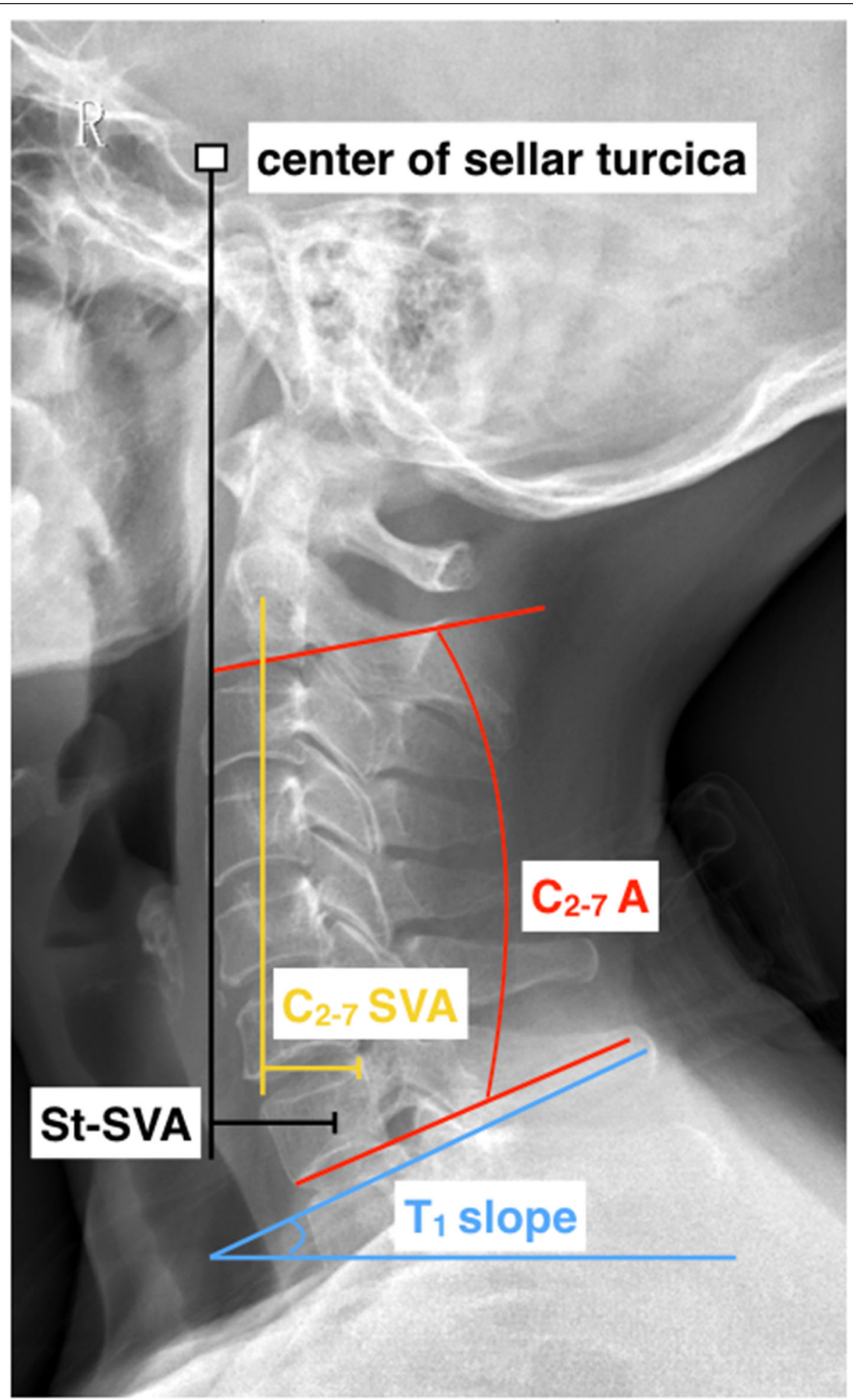

Fig. 2 Lateral cervical spine radiograph with an illustration of key cervical sagittal alignment measurements. SVA indicates the sagittal vertical axis. $\mathrm{C}_{2-7}$ A represents the $\mathrm{C} 2-\mathrm{C} 7$ angle

counting data are expressed as (\%). The independent $\mathrm{t}$ test and chi-square analysis were used when the normality assumption was satisfied, and the Mann-Whitney U- test was used when the normality assumption was not satisfied in the Kolmogorov-Smirnov test. A $P$ value $<$ 0.05 was considered statistically significant. 


\section{Results}

\section{Patient demographics}

A total of 87 patients met the inclusion criteria, and 37 patients were included in ACDF with UT group and 50 patients were included in each group. The mean followup was $16.86 \pm 5.63$ and $18.36 \pm 7.51$ months in the ACDF with UT group and ACDF without UT group, respectively $(p>0.05)$ (Table 1$)$. No significant differences were found in age, sex, BMI, blood loss, hospital stay or level distribution between the two groups (Table 1).

\section{Comparison of clinical parameters}

There were no significant differences in preoperative JOA, Neck-VAS, or NDI between the two groups. The average preoperative VAS arm score was $5.70 \pm 1.05$ in the uncinatectomy group and $5.18 \pm 1.21$ in the nonuncinatectomy group. The preoperative Arm-VAS score in the uncinatectomy group was significantly higher than that in the non-uncinatectomy group $(p=0.038$, Table 2$)$. All patients showed pain relief and neurologic improvement after surgery, and no significant postoperative differences were found in clinical parameters between the two groups.

\section{Comparison of cervical sagittal alignment}

Cervical sagittal alignment parameters are shown in Table 3. With the exception of C2-7 SVA and St-SVA, the other sagittal alignment parameters were similar at various time points $(p>0.05)$. In the uncinatectomy group, the C2-7 SVA was maintained from $18.67 \pm 6.08$ $\mathrm{mm}$ before surgery to $18.62 \pm 6.33 \mathrm{~mm}$ at the last follow-up, with a mean change value of $-0.05 \pm 6.22 \mathrm{~mm}$. In the non-uncinatectomy group, it decreased from
Table 2 Clinical outcomes of two groups

\begin{tabular}{llll}
\hline & ACDF with UT & ACDF without UT & $\boldsymbol{P}$ \\
\hline JOA scores & & & \\
preoperative & $11.11 \pm 2.23$ & $10.90 \pm 1.98$ & 0.648 \\
1 week & $12.72 \pm 1.65$ & $12.44 \pm 1.86$ & 0.495 \\
Last follow-up & $15.59 \pm 1.57$ & $15.72 \pm 1.39$ & 0.690 \\
VAS neck score & & & \\
preoperative & $5.89 \pm 1.00$ & $5.66 \pm 1.08$ & 0.443 \\
1 week & $4.23 \pm 0.81$ & $4.16 \pm 0.65$ & 0.722 \\
Last follow-up & $1.97 \pm 1.10$ & $1.64 \pm 0.83$ & 0.105 \\
VAS arm score & & & \\
preoperative & $5.70 \pm 1.05$ & $5.18 \pm 1.21$ & $\mathbf{0 . 0 3 8 ^ { * }}$ \\
1 week & $4.22 \pm 0.64$ & $4.06 \pm 1.13$ & 0.451 \\
Last follow-up & $1.68 \pm 0.71$ & $1.60 \pm 0.70$ & 0.621 \\
NDI scores & & & \\
preoperative & $24.11 \pm 3.76$ & $22.96 \pm 5.65$ & 0.586 \\
1 week & $17.81 \pm 3.58$ & $16.76 \pm 5.23$ & 0.621 \\
Last follow-up & $10.99 \pm 4.95$ & $9.71 \pm 2.82$ & 0.586 \\
\hline Indicates statistically significant differences $(\boldsymbol{p}<0.05)$ &
\end{tabular}

$19.84 \pm 7.00 \mathrm{~mm}$ before surgery to $15.75 \pm 6.02 \mathrm{~mm}$ at the last follow-up, and the mean change value was $4.09 \pm 9.21$. There were significant differences between the groups in the C2-7 SVA at the last follow-up ( $p=$ $0.034)$ and the mean changes in C2-7 SVA values ( $p=$ 0.023 ) (Table 3). In addition, the St-SVA decreased from $28.09 \pm 5.83 \mathrm{~mm}$ to $26.25 \pm 10.64 \mathrm{~mm}$ in the uncinatectomy group, with a mean change of $-2.49 \pm 12.51$, and $29.86 \pm 6.69 \mathrm{~mm}$ to $22.15 \pm 8.44 \mathrm{~mm}$ in the non-

Table 1 Demographic and baseline data (mean \pm SD)

\begin{tabular}{llll}
\hline Groups & ACDF with UT $(\boldsymbol{N}=\mathbf{3 7})$ & ACDF without UT $(\boldsymbol{N}=\mathbf{5 0})$ & $\boldsymbol{p}$ \\
\hline Age (years) & $51.46 \pm 9.47$ & $53.47 \pm 10.36$ & 0.206 \\
Gender (female/male) & $17 / 20$ & $22 / 28$ \\
BMl $\left(\mathrm{kg} / \mathrm{m}^{2}\right)$ & $23.55 \pm 2.64$ & $23.95 \pm 2.60$ \\
Smoking (yes/no) & $14 / 23$ & $18 / 32$ \\
Alcohol (yes/no) & $8 / 29$ & $13 / 37$ \\
Blood loss (ml) & $79.03 \pm 51.21$ & $76.62 \pm 62.57$ \\
Hospital stay (days) & $8.64 \pm 2.27$ & $8.24 \pm 2.36$ \\
Operation level & & \\
C3/4 & 2 & 8 \\
C4/5 & 5 & 8 \\
C5/6 & 26 & 32 \\
C6/7 & 4 & 2 \\
Follow-up & $16.86 \pm 5.63$ & $18.36 \pm 7.51$ \\
\hline ACDF & & 0.422 \\
\hline
\end{tabular}

$A C D F$ anterior cervical discectomy and fusion, UT uncinatectomy, BMI body mass index $p<0.05$ was the criterion for statistical significance 
Table 3 Radiographic assessments of patients in three groups (mean \pm SD)

\begin{tabular}{|c|c|c|c|}
\hline Group & ACDF with UT & ACDF without UT & $p$ \\
\hline \multicolumn{4}{|l|}{$\mathrm{C} 2-7 \mathrm{~A}\left({ }^{\circ}\right)$} \\
\hline preoperative & $14.23 \pm 5.06$ & $12.93 \pm 7.00$ & 0.345 \\
\hline 1 week & $13.26 \pm 8.13$ & $11.96 \pm 6.46$ & 0.176 \\
\hline Last follow-up & $12.78 \pm 7.49$ & $11.25 \pm 6.62$ & 0.317 \\
\hline $\mathrm{d} C 2-7 \mathrm{~A}\left({ }^{\circ}\right)$ & $-1.45 \pm 8.45$ & $-1.69 \pm 7.72$ & 0.874 \\
\hline \multicolumn{4}{|l|}{ FSUA $\left(^{\circ}\right)$} \\
\hline preoperative & $3.24 \pm 1.93$ & $3.37 \pm 1.89$ & 0.875 \\
\hline 1 week & $3.12 \pm 1.88$ & $3.21 \pm 1.87$ & 0.826 \\
\hline Last follow-up & $3.05 \pm 1.80$ & $3.09 \pm 1.93$ & 0.914 \\
\hline dFSUA $\left(^{\circ}\right)$ & $-0.25 \pm 0.58$ & $-0.28 \pm 0.59$ & 0.862 \\
\hline \multicolumn{4}{|l|}{ C2-7 SVA (mm) } \\
\hline preoperative & $18.67 \pm 6.08$ & $19.84 \pm 7.00$ & 0.417 \\
\hline 1 week & $18.32 \pm 6.03$ & $18.17 \pm 6.99$ & 0.915 \\
\hline Last follow-up & $18.62 \pm 6.33$ & $15.75 \pm 6.02$ & $0.034 *$ \\
\hline dC2-7 SVA (mm) & $-0.05 \pm 6.22$ & $-4.09 \pm 9.21$ & $0.023 *$ \\
\hline \multicolumn{4}{|l|}{ St-SVA (mm) } \\
\hline preoperative & $28.09 \pm 5.83$ & $29.86 \pm 6.69$ & 0.417 \\
\hline 1 week & $24.80 \pm 6.36$ & $25.17 \pm 5.39$ & 0.052 \\
\hline Last follow-up & $26.25 \pm 10.64$ & $22.15 \pm 8.44$ & $0.033 *$ \\
\hline dSt-SVA (mm) & $-2.49 \pm 12.51$ & $-7.70 \pm 8.44$ & $0.019 *$ \\
\hline \multicolumn{4}{|l|}{ T1 slope $\left(^{\circ}\right)$} \\
\hline preoperative & $27.92 \pm 6.66$ & $26.29 \pm 6.30$ & 0.229 \\
\hline 1 week & $26.55 \pm 5.19$ & $27.00 \pm 5.71$ & 0.709 \\
\hline Last follow-up & $26.79 \pm 6.20$ & $27.19 \pm 7.07$ & 0.784 \\
\hline dT1 slope $\left({ }^{\circ}\right)$ & $-1.18 \pm 5.69$ & $0.91 \pm 7.23$ & 0.149 \\
\hline
\end{tabular}

SD standard deviation, C2-7 A C2-7 angle; FSUA, functional spinal unit angle,C2-7 SVA C2-7 sagittal vertical axis, St-SVA sellar turcica-sagittal vertical axis

$d$ : the difference of parameters at last follow-up and preoperative *Indicates statistically significant differences $(p<0.05)$

uncinatectomy group at the last follow-up, with a mean change of $-7.70 \pm 8.44$. There were significant differences between the groups in the St-SVA at the last follow-up $(p=0.033)$ and changes in the St-SVA values $(p=0.019)$ (Table 3; Figs. 3 and 4).

\section{Comparison of the complications and fusion rate}

During the follow-up period, there were no serious complications that required revision surgery. There were no significant differences in the occurrence of dysphagia, adjacent segment degeneration (ASD) or cage subsidence. At the time of the last follow-up, the fusion rates were 97.30 and $96 \%$ in the two groups, respectively ( $p=$ 0.743 , Table 4).

\section{Discussion}

Uncovertebral joint is common site for osteoarthritic changes [22]. These changes manifest as pitting and eburnation of the articular surfaces and distortion of the uncinate process as osteophytic spurring develops. Osteophytes that arise from the posterior aspect of the uncinate process project into the intervertebral foramen and compress its contents. Despite this, there are various opinions on the treatment of CSR patients with foraminal stenosis. Riley et al. thought that with the establishment of spinal stability and the release of abnormal stress stimuli, osteophytes can spontaneously be absorbed [23]. Shen et al. [13] conducted a retrospective study to analyse the necessity of direct uncovertebral joint decompression during $\mathrm{ACDF}$, and they found that ACDF with or without direct uncovertebral joint decompression can provide good clinical results for neck pain with cervical radiculopathy. Cloward considered that all factors that compress nerve roots should be removed in anterior cervical surgery, including uncovertebral osteophytes [24]. Therefore, routine direct uncovertebral joint decompression should not be undertaken during ACDF. In contrast, Park et al. [25] reported that ACDF with uncinatectomy can provide a better long-term outcome with minimal ASD. In our study, there were no significant differences in postoperative VAS arm and neck scores, which indicates that ACDF with uncinatectomy was not superior than ACDF without uncinatectomy in terms of clinical efficacy.

The cervical spine is the part of the spine with the most mobility in the sagittal plane [2]. During the last decade, the study of cervical sagittal balance became highlighted as it links functionality and the surgical outcome [26]. To the best of our knowledge, only one article has reported the effect of uncinatectomy on sagittal balance after one-level ACDF with a cage-and-plate construct [21]. They found that cervical sagittal alignment after ACDF with uncinatectomy was not significantly different from that achieved with ACDF without uncinatectomy; however, the occurrence of subsidence was higher in the ACDF with uncinatectomy group. In this study, similar results in sagittal alignment were obtained. Although a higher cage subsidence rate $(8 \%)$ was observed in the ACDF with uncinatectomy group, the difference between the two groups did not reach statistical significance $(p=0.388$, Table 4$)$. It was reported that various factors including cage type [27] and location [28], distractive force [29], end-plate preparation [30], and particularly, a small degree of segmental instability (micro-motion) [31, 32] may affect subsidence. Lee et al. [33] investigated the effect of UT on the subsidence following ACDF using a anterior plate fixation. The UT, especially uncinate process resection area $>38 \%$, significantly increase the micro-motion between plate and 


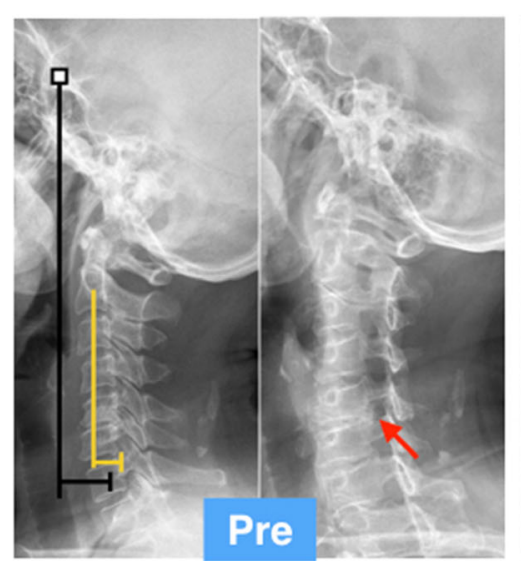

\section{$\mathrm{C}_{2-7} \mathrm{SVA}=16.7 \mathrm{~mm}$ St - SVA $=26.2 \mathrm{~mm}$}

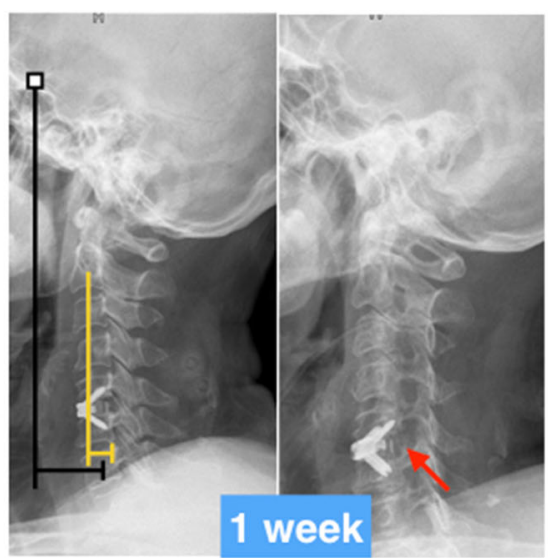

$\mathrm{C}_{2-7} \mathrm{SVA}=11.2 \mathrm{~mm}$ St - SVA $=28.6 \mathrm{~mm}$

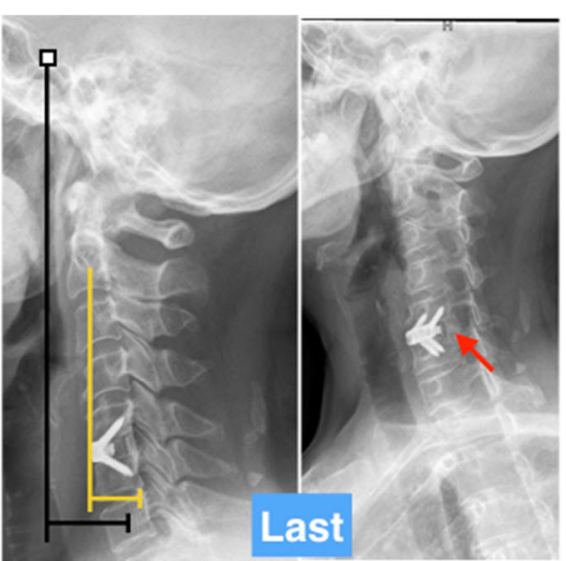

$\mathrm{C}_{2-7} \mathrm{SVA}=19.5 \mathrm{~mm}$ St - SVA $=30.3 \mathrm{~mm}$

Fig. 3 A 58-year-old woman was diagnosed with cervical radiculopathy combined with foraminal stenosis caused by uncovertebral joint hyperplastic osteophytes, which can be seen on preoperative right oblique imaging (red arrow). The patient underwent ACDF with partial uncinatectomy. The improvement of C2-7 SVA and St-SVA was not obvious after the surgery

bone interface and the possibility of subsidence will increased.

C2-7 SVA is thought to be the best indicator of cervical malalignment, and it was reported that it has a close relationship with clinical outcomes after cervical surgery $[25,41,42]$. As another representative factor for estimating radiological outcome, St-SVA was also demonstrated to be related to postoperative neck pain and health-related quality of life (HRQOL) [28,43,44]. However, C2-7 SVA and St-SVA were not reflected in postoperative neck pain or quality of life in our study. A possible reason for this dissimilarity is that the incidence, severity and mechanisms underlying postoperative neck pain differed between the anterior and posterior cervical surgeries. In our study, C2-7 SVA and St-SVA of ACDF without UT group were restored from

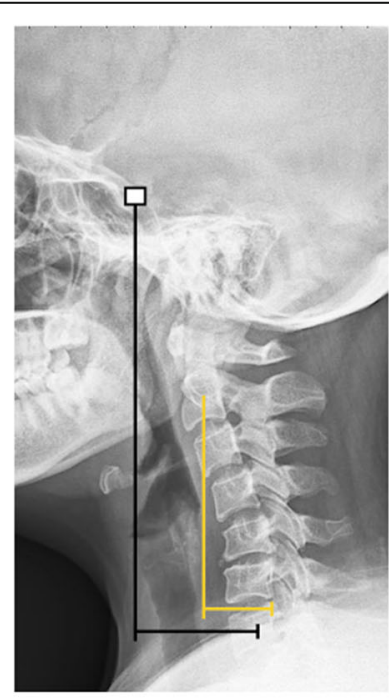

$\mathrm{C}_{2-7} \mathrm{SVA}=22.1 \mathrm{~mm}$ St - SVA = $35.1 \mathrm{~mm}$

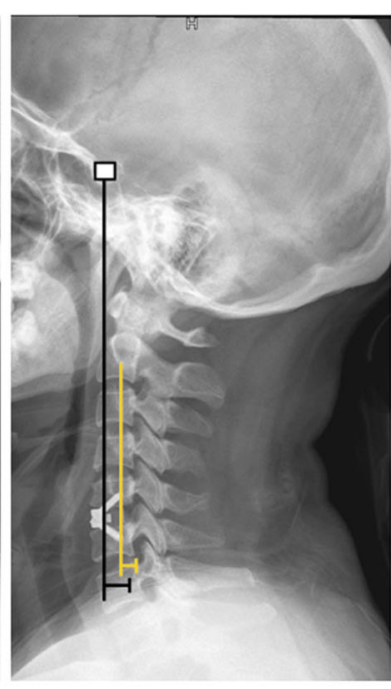

$\mathrm{C}_{2-7} \mathrm{SVA}=11.2 \mathrm{~mm}$ St - SVA = $16.3 \mathrm{~mm}$

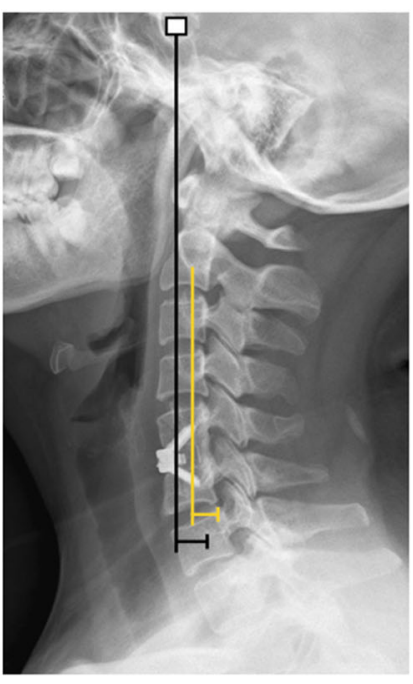

$\mathrm{C}_{2-7} \mathrm{SVA}=10.5 \mathrm{~mm}$ St - SVA = $11.2 \mathrm{~mm}$

Fig. 4 A case from the ACDF without uncinatectomy group. The C2-7 SVA and St-SVA decreased significantly over time 
Table 4 Comparison of complications among three groups

\begin{tabular}{llll}
\hline Groups & ACDF with UT $(\boldsymbol{N}=\mathbf{3 7})$ & ACDF without UT $(\boldsymbol{N}=\mathbf{5 0})$ & $\boldsymbol{p}$ \\
\hline Dysphagia & $8.11 \%(3)$ & $8.00 \%(4)$ & 0.985 \\
ASD & $10.81 \%(4)$ & $12 \%(6)$ & 0.863 \\
Cage subsidence & $16.22 \%(6)$ & $10 \%(5)$ & 0.388 \\
Fusion rates & $97.30 \%(36)$ & $96 \% 48)$ & 0.743 \\
\hline
\end{tabular}

$A C D F$ anterior cervical discectomy and fusion, UT uncinatectomy

$19.84 \pm 7.00 \mathrm{~mm}$ to $15.75 \pm 6.02 \mathrm{~mm}$ and $29.86 \pm \mathrm{z} 6.69 \mathrm{~mm}$ from $22.15 \pm 8.44 \mathrm{~mm}$ at the last follow-up and this trend was similar with the previous studies [21, 34, 35]. SVA is an important evaluation index of the degree of the overall cervical displacement. Our findings demonstrated that the ACDF itself, which using a zero profile device, can restore the displacement of the center of gravity and sagittal alignment of cervical spine to some extent, which may subsequently reduce the energy expenditure of the neck and shoulder muscles. Besides, ACDF without UT group is superior to ACDF with UT group in terms of improving C2-7 SVA and St-SVA. Although we are unable to analyze exact mechanism in a retrospective study, we speculated a possible reason according to our result: foraminal part of the uncovertebral joint may plays important role in restricting the lateral displacement of lower cervical spine. Further biomechanical studies are needed to verify this.

Clausen et al. [12] analysed the biomechanical significance of uncinate processes and found that if uncinate processes are resected during surgery, primary motion will increase relative to intact motion. Thus, they suggested the use of a fusion procedure to reduce lateral bending instability resulting from resection of the uncinate processes during ACDF. It was reported that the uncovertebral joint contributes $48-60 \%$ of the total stability at each level, with the posterior aspect of the uncovertebral joint providing the greatest stability [13]. Although total uncinatectomy has been reported to be an effective method [15-18], we agree that in the process of uncovertebral joint decompression, removing the hyperplastic osteophytes and foraminal part of the uncovertebral joint would be sufficient to relieve nerve root compression, and the procedure also reduces injury to the vertebral artery to a certain extent. In addition, because the uncovertebral joint has rich venous vessels, serious haemorrhage may be more likely to occur during total uncinatectomy.

\section{Limitations}

Our study has some limitations. First, this is a singlecentre, retrospective, nonrandomized controlled study with a relatively small number of cases. Second, the average follow-up of these patients was $17.72 \pm 6.78$ months, which severely limited our analysis of long-term outcomes. In addition, although two spine surgeons measured the radiological parameters with reference to previously published reports, we acknowledge that potentially inherent radiographic imaging error may be another limitation. Furthermore, it is challenging to precisely evaluate the degeneration of adjacent segments without postoperative MRI imaging of the cervical spine. However, we can still adequately assess ASD according to the abovementioned radiographic criteria. Another major limitation is that we did not include the patients with bilateral uncinatectomy. The main reason is that the number of patients who underwent bilateral uncinatectomy was much smaller than that of patients who underwent unilateral uncinatectomy in our department. Last, we did not analyse the effect of uncinatectomy on the thoracolumbar region or spine-pelvic sagittal balance. We hope future studies, especially biomechanical studies, can answer these questions.

\section{Conclusions}

Our result indicates that ACDF using a zero-p implant with or without partial UT both provide satisfactory clinical efficacy and acceptable safety. However, additional partial UT may has a negative effect on cervical sagittal alignment.

\section{Abbreviations}

CSR: Cervical spondylotic radiculopathy; UT: Uncinatectomy; ACDF: Anterior cervical discectomy and fusion; PCC: Plate-cage construct; Zero-P: Zeroprofile device; BMI: Body mass index; VAS: Visual analogue scale; NDI: Neck Disability Index; JOA: Japanese Orthopaedic Association; CL: Cervical lordosis; FSUA: Functional spinal unit angle; SVA: Sagittal vertical axis; St-SVA: Sella turcica-C7 sagittal vertical axis; ASD: Adjacent segment degeneration; HRQOL: Health-related quality of life

\section{Acknowledgements}

None.

\section{Authors' contributions}

H.A.: Methodology, Writing - original draft; T.W. : Investigation, Writing, Validation, Software; H.L. : Conceptualization, Methodology, Writing - original draft; B.W. : Investigation, Validation, Resources; H.C. : Supervision, Software; C.H. : Writing, review \& editing; Y.H. : Data curation, Resources; Y.M. : Data curation, Resources. The author(s) read and approved the final manuscript.

\section{Funding}

This study was supported by the Sichuan Province Science and Technology Support Program (grant no. 2019YFQ0002 to Hao Liu, grant no. 2020YFS0084 to Beiyu Wang, grant no. 2019 YFS0135 to Hua Chen), and the West China Nursing Discipline Development Special Fund Project (grant no. HXHL 19016 to Ying Hong). 


\section{Availability of data and materials}

The datasets used and/or analysed during the current study are available from the corresponding author on reasonable request.

\section{Declarations}

\section{Ethics approval and consent to participate}

All methods were performed in accordance with the relevant guidelines and regulations. Ethical approval was granted by the Human Research Ethics Committees of West China Hospital of Sichuan University and Health and Medical Research. (No. 2020(417)). Written informed consent was obtained from individual or guardian participants.

\section{Consent for publication}

The all author confirm that this study described has not been published before, and it is not under consideration for publication elsewhere. Written informed consent for publication was obtained from all participants.

\section{Competing interests}

The authors declare that they have no competing interests.

\section{Author details}

'Department of Orthopedic Surgery, West China Hospital, Sichuan University, No. 37 Guo Xue Xiang Rd, Chengdu, China. ${ }^{2}$ Department of Anesthesia and Operation Center, West China school of Nursing, West China Hospital, Sichuan University, Chengdu, China.

Received: 28 July 2021 Accepted: 26 August 2021

Published online: 12 September 2021

\section{References}

1. Kelsey JL, Githens PB. An epidemiological study of acute prolapsed cervical intervertebral disc. J Bone Joint Surg Am. 1984;66(6):907-14.

2. Safaee MM, Nichols NM. Safety and efficacy of direct nerve root decompression via anterior cervical discectomy and fusion with uncinectomy for cervical radiculopathy. J Spine Surg. 2020;6(1):205-9.

3. Bohlman HH, Emery SE, et al. Robinson anterior cervical discectomy and arthrodesis for cervical radiculopathy. Long-term follow-up of one hundred and twenty-two patients. J Bone Joint Surg Am. 1993;75(9):1298-307.

4. Wang Z, Zhu R. Zero-profile implant (Zero-p) versus plate cage benezech implant (PCB) in the treatment of single-level cervical spondylotic myelopathy. BMC Musculoskelet Disord. 2015;16:290.

5. Li T, Yang JS. Can zero-profile cage maintain the cervical curvature similar to plate-cage construct for single-level anterior cervical diskectomy and fusion? World Neurosurg. 2020;135:e300-6.

6. Fraser JF, Härtl R. Anterior approaches to fusion of the cervical spine: a metaanalysis of fusion rates. J Neurosurg Spine. 2007;6(4):298-303.

7. Brigham CD, Tsahakis PJ. Anterior cervical foraminotomy and fusion. Surgical technique and results. Spine. 1995;20(7):766-70.

8. Davis RA. A long-term outcome study of 170 surgically treated patients with compressive cervical radiculopathy. Surg Neurol. 1996;46(6):523-33.

9. Jho HD. Microsurgical anterior cervical foraminotomy for radiculopathy: a new approach to cervical disc herniation. J Neurosurg. 1996;84(2):155-60.

10. Civelek E, Kiris T. Anterolateral approach to the cervical spine: major anatomical structures and landmarks. Technical note. J Neurosurg Spine. 2007;7(6):669-78.

11. Uğur HC, Uz A. Anatomical projection of the cervical uncinate process in ventral, ventrolateral, and posterior decompressive surgery. J Neurosurg. 2000;93(2 Suppl):248-51.

12. Clausen JD, Goel VK. Uncinate processes and Luschka joints influence the biomechanics of the cervical spine: quantification using a finite element model of the C5-C6 segment. J Orthop Res. 1997;15(3):342-7.

13. Shen FH, Samartzis D. Comparison of clinical and radiographic outcome in instrumented anterior cervical discectomy and fusion with or without direct uncovertebral joint decompression. Spine J. 2004;4(6):629-35.

14. Lee $\mathrm{DH}, \mathrm{Cho} \mathrm{JH}$. Does additional uncinate resection increase pseudarthrosis following anterior cervical discectomy and fusion? Spine. 2018;43(2):97-104.

15. Clifton W, Williams D. How I do it: total uncinatectomy during anterior diskectomy and fusion for cervical radiculopathy caused by uncovertebral joint hypertrophy. Acta Neurochir. 2019;161(10):2229-32.
16. Pakzaban P. Ultrasonic total uncinectomy: a novel technique for complete anterior decompression of cervical nerve roots. Neurosurgery. 2014;10(Suppl 4):535-41.

17. Valero-Moreno F, Clifton W. Total anterior uncinatectomy during anterior discectomy and fusion for recurrent cervical radiculopathy: a twodimensional operative video and technical report. Cureus. 2020;12(3):e7466.

18. Clifton, W., \& Pichelmann, M. Letter to the Editor. Safety in the use of a high-speed burr for total uncinectomy during ACDF. J Neurosurg Spine. 2019 Nov 15:1-2.

19. Kotani Y, McNulty PS. The role of anteromedial foraminotomy and the uncovertebral joints in the stability of the cervical spine. A biomechanical study. Spine. 1998;23(14):1559-65.

20. Ohara A, Miyamoto K. Reliabilities of and correlations among five standard methods of assessing the sagittal alignment of the cervical spine. Spine. 2006:31(22):2585-92.

21. Noh SH, Park JY. Association of complete uncinate process removal on 2year assessment of radiologic outcomes: subsidence and sagittal balance in patients receiving one-level anterior cervical discectomy and fusion. BMC Musculoskelet Disord. 2020;21(1):439.

22. Hartman J. Anatomy and clinical significance of the uncinate process and uncovertebral joint: a comprehensive review. Clin Anat. 2014;27(3):431-40.

23. Riley LH Jr, Robinson RA, Johnson KA, Walker AE. The results of anterior interbody fusion of the cervical spine. Review of ninety-three consecutive cases. J Neurosurg. 1969;30(2):127-33.

24. Cloward R. B. The anterior approach for removal of ruptured cervical disks 1958. J Neurosurg Spine. 2007;6(5):496-511.

25. Park YK, Moon HJ. Long-term outcomes following anterior foraminotomy for one- or two-level cervical radiculopathy. Eur Spine J. 2013;22(7):1489-96.

26. Fehlings MG, Gray R. Importance of sagittal balance in determining the outcome of anterior versus posterior surgery for cervical spondylotic myelopathy. J Neurosurg Spine. 2009;11(5):518-20.

27. Bartels RH, Donk RD, Feuth T. Subsidence of stand-alone cervical carbon fiber cages. Neurosurgery. 2006;58(3):502-8

28. Park JY, Choi KY. Subsidence after single-level anterior cervical fusion with a stand-alone cage. J Clin Neurosci. 2016;33:83-8.

29. Francke El, Demetropoulos. Distractive force relative to initial graft compression in an in vivo anterior cervical discectomy and fusion model. Spine. 2010;35(5):526-30.

30. Lim $\mathrm{TH}, \mathrm{Kwon} \mathrm{H}$, Jeon $\mathrm{CH}$. Effect of endplate conditions and bone mineral density on the compressive strength of the graft-endplate interface in anterior cervical spine fusion. Spine. 2001;26(8):951-6.

31. Wu SH, Li Y, Zhang YQ. Porous titanium-6 aluminum-4 vanadium cage has better osseointegration and less micromotion than a poly-ether-etherketone cage in sheep vertebral fusion. Artif Organs. 2013;37(12):E191-201.

32. Kettler A, Wilke HJ, Claes L. Effects of neck movements on stability and subsidence in cervical interbody fusion: an in vitro study. J Neurosurg. 2001; 94(1 Suppl):97-107.

33. Lee SH, Lee JS, Sung SK. The effect of uncinate process resection on subsidence following anterior cervical discectomy and fusion. J Korean Neurosurg Soc. 2017;60(5):550-9.

34. Hyun SJ, Kim KJ. Relationship between t1 slope and cervical alignment following multilevel posterior cervical fusion surgery: impact of $\mathrm{T} 1$ slope minus cervical lordosis. Spine. 2016;41(7):E396-402.

35. Kwon WK, Kim PS. Analysis of associating factors with C2-7 sagittal vertical axis after two-level anterior cervical fusion: comparison between plate augmentation and stand-alone cages. Spine. 2017:42(5):318-25.

\section{Publisher's Note}

Springer Nature remains neutral with regard to jurisdictional claims in published maps and institutional affiliations. 